\title{
Infection prevention and control curriculum in undergraduate nursing program: Internship nursing students' perspectives
}

\author{
Thoraya Abdelaziz, Rawhia Dogham, Nermine Elcockany \\ Faculty of Nursing, Alexandria University, Edmon Fremon St. Smouha, Alexandria, Egypt
}

Received: March 26, 2019

Accepted: June 30, 2019

Online Published: July 15, 2019

DOI: $10.5430 /$ jnep.v9n10p59

URL: https://doi.org/10.5430/jnep.v9n10p59

\begin{abstract}
Undergraduate nursing education plays a vital role in acquiring the necessary competency for patient safety. Infection prevention and control is a very critical topic for providing patient safety so, undergraduate and graduate nursing students should be competent in infection prevention and control. The aim of this study was to measure the undergraduate nursing program effectiveness in improving knowledge and practice of infection prevention and control of internship nursing students and to identify their learning needs. A descriptive research design was used. Students were selected using convenience sampling which included 400 internship nurses. Data was collected using a self-reported questionnaire. The results of the current study displayed that more than half (59.5\%) of the intern nurses had poor knowledge and also $43.2 \%$ of them had poor practice. In addition, it was found that more than half of them reported that infection control program is neither irrelevant nor meaningful, and $48.5 \%$ of the students suggested that participation in infection prevention and control training is most important for the improvement of nursing program. This study concluded that infection prevention and control topics in undergraduate nursing education may be insufficient and need to be updated, as well as the need for reviewing the intended learning outcomes of nursing program to ensure the addition and implementation of infection control guidelines in all undergraduate in the last academic year of nursing program as well as internship. The students also are in need for continued training and education regarding guidelines of infection prevention and control practice.
\end{abstract}

Key Words: Infection control, Universal precautions, Intern nurses, Infection prevention and control guidelines, Nursing program

\section{INTRODUCTION}

Infection prevention and control (IPC) is a rapidly changing field. Infection is defined as the development of microorganisms in the human body. In other words, it can be defined as the body's invasion with agents which have the possibility to cause disease. ${ }^{[1]}$ Infection control is also a field focusing on preventing nosocomial and healthcare-associated infection.
Health care-associated infection (HAI) is considered as one of the critical issues in healthcare. Such infections have both a load on the patient as well as the healthcare organization because it may lead to disability, suffering, psychological problems, delay in recovery, morbidity, longer hospital stay, staff workload and further hospital costs. ${ }^{[2]}$

In 2011, the World Health Organization (WHO) described

\footnotetext{
*Correspondence: Rawhia Dogham; Email: Dr.rawhia_edu@yahoo.com; Address: Faculty of Nursing, Alexandria University, Edmon Fremon St. Smouha, Alexandria, Egypt.
} 
that about $7 \%$ of patients in the developed countries and $15 \%$ in the low and middle income countries experienced slightly one HAI at any given time, with approximately $10 \%$ of mortality rate. ${ }^{[3,4]}$ In 2011, it was also reported that nosocomial infections represent $10 \%$ in developing countries and $7 \%$ in developed countries. ${ }^{[5]}$

The risk is significant not only for patients, but also for health care workers (HCWs), including nursing students. According to the WHO reports approximately 3 million have percutaneous exposures to blood borne pathogens each year such as HBV, HCV and HIV. These injuries may lead to 15,000 $\mathrm{HCV}, 70,000 \mathrm{HBV}$ and $500 \mathrm{HIV}$ infections out of 35 million of HCWs internationally. More than $90 \%$ of these infections arise in developing countries. Applying IPC guidelines will prevent the most of these infections. ${ }^{[6]}$ Among the infection control guidelines, hand hygiene is considered the most important practice. Another essential principle is the proper use of personal protective equipment (PPE). Moreover, the implementation of safe practices for handling needle sticks and other sharp objects is essential to prevent the occurrence of Hepatitis B and C for the HCWs. ${ }^{[7]}$

Nurses are the largest section of the HCWs. They are considered as the "heart of the healthcare system" as they spend with the patients more time than any other HCWs. Their compliance with IPC guidelines is very important for preventing the disease transmission among patients. Thus, applying IPC guidelines by nurses is considered as a cornerstone of heath care system and the most important issue for lowering the prevalence of HAIs. ${ }^{[7]}$

Nursing students are viewed as a part of healthcare workers in clinical training placements including the internship nurses. They are exposed early to activities such as direct patients contact during their clinical practice; they might be the source of transmitting infection due to their limited knowledge and experience about infection control practices. ${ }^{[8,9]}$ Accordingly, the undergraduate nursing program should prepare those intern nurses with the necessary knowledge, skills and attitudes related to safe nursing practice. ${ }^{[10]}$

Therefore, it has been reported that IPC education needs to be included in the orientation program of all healthcare staff with a special focus on novice nurses, doctors and the internship students ${ }^{[11]}$ and it has to be considered as a part of their personal development plans. However, various studies have been reported that; nursing students have a low level of knowledge regarding IPC and poor transfer of that knowledge to their clinical practice. Consequently, there is a poor compliance of students concerning IPC practices in undergraduate nursing program. ${ }^{[12,13]}$
In developing countries including Egypt, studies have shown a very low compliance by professionals and students alike. For that reason, undergraduate nursing program should include intended learning outcomes relevant to IPC which needs to be met and achieved by the nursing students. ${ }^{[14,15]}$

Although IPC competency among nursing students and graduates is considered a significant and ongoing global issue, only few studies consider this area. Thus, the teaching and practice requirements of undergraduate nursing students regarding these issues need to be addressed. Furthermore, the ongoing review of the nursing undergraduate courses is vital to provide a worldwide overview of this aspect. The aim of this study was to measure the usefulness of undergraduate nursing program in improving nursing students' knowledge and practice of IPC as well as to identify their learning needs.

\section{MATERIALS AND METHOD}

\subsection{Study design}

A descriptive research design was used to conduct this study. The current study was carried out at the concerned setting. The study data was collected throughout July 2018. A convenience sample of 400 out of 470 internship nursing students agreed to participate in this study before starting their internship training program. Old internship nursing students were excluded from the current study.

\subsection{Measures}

One tool was used for data collection namely "Infection Prevention \& Control Structured Questionnaire". It was developed by the researchers after reviewing the relevant literatures. ${ }^{[16-21]}$ It is used to assess internship nursing students' perspective regarding the IPC knowledge and practices taught in the undergraduate nursing program. It consists of four parts. Part (I): Socio-demographic data that include: internship nursing students' age, gender, previous educational level and previous infection control training program attendance. Part (II): Internship nursing students' knowledge related to IPC guidelines. This part is aimed to assess internship nursing students' knowledge of IPC. It consists of 21 multiple choice questions and 27 true and false questions. It includes knowledge related to hand hygiene, isolation precautions, respiratory cough etiquette and hygiene, use of PPE, cleaning and disinfection of medical equipment. Part (III): Internship nursing students' perspectives regarding IPC practices in nursing program. It is used to measure the students' perspectives of the IPC practices which are already taught in nursing program. This part includes 8 statements, the answers are scored on four-point Likert scales range from: always $(=4)$ to never $(=0)$. Part (IV): Internship nursing students' satisfaction with nursing program regarding IPC. 
It includes 10 statements which answered using a four-point Likert scales ranged from: strongly agree $(=3)$ to strongly disagree $(=0)$. Questions from 11 to 15 illustrated information regarding the participants' perspectives about the educational environment which support the IPC behaviors. The internship nursing students' knowledge and practice cut of scores were established and calculated then summarized and converted to percent score which classified as Poor, for those who have a score $<50.0 \%$, fair, for those who have a score of $50.0 \%$ to $<75.0 \%$ and good, for those who have a score $\geq 75.0 \%$. In addition, the nursing students' satisfaction regarding IPC curriculum in nursing program were summarized and converted to percent score as: the data are relevant and meaningful for a score $>70 \%$, while they are neither irrelevant nor meaningful when the score was $\leq 65 \%$.

\subsection{Study procedures}

An official permission was obtained from the administrative authorities at the Faculty of Nursing; for their approval for collecting data after explanation of the purpose of the study. The tool was developed by the researchers after extensive review of the related literature. After that, it was tested for content validity by five experts in the related study field and the needed modifications were made. Pilot study was performed on $10 \%(n=47)$ of internship nursing students before starting the data collection to test the clarity of the study tools, and then necessary modifications were made. Participants of the pilot study were excluded from the study sample. Reliability of the tool was tested on pilot study by using Cronbach's Alpha coefficient statistical test which revealed an accepted value of 0.72 . It took from 20 to 30 minutes for each student to complete the sheet. Any instruction statements were given to all students during filling the questionnaire. Ethical considerations were achieved by explaining the purpose of the study. Students were assured that this study is for educational purpose only. Students' information and responses were treated anonymously and confidentiality was assured. In addition, an informed consent was obtained from the all students and the right to withdraw from the study was respected.

\subsection{Statistical analysis of the data}

Data were fed to the computer and analyzed using IBM SPSS software package version 20.0. (Armonk, NY: IBM Corp) Quantitative data were described using number and percent, range (minimum and maximum), as well as mean and standard deviation. Significance of the obtained results was judged at the $5 \%$ level. The used tests were Chi-square test for categorical variables, to compare between different groups and Pearson coefficient to correlate between two normally distributed quantitative variables.

\section{RESULTS}

\subsection{Sociodemographic characteristics}

In total 400 students participated in the study whereas 23 students were missed (response rate $=94.5 \%$ ).

As shown in Table 1, the distribution of internship nursing students in relation to their socio-demographic characteristics. It can be found that the highest percentage of the students (87\%) age ranges from 20-23 years old while $13 \%$ only where beyond 24 years old with a mean score of 22.50 \pm 1.11 . More than two thirds $(71.2 \%)$ of the students were females; whereas $28.8 \%$ were males. Regarding level of education, the majority of them $(80.75 \%)$ had a secondary school certificate before joining the university. Regarding attendance of training program, $65.2 \%$ never attends any continuing training program about infection control for selfdevelopment.

Table 1. Distribution of internship nursing students according to their socio demographic data $(n=400)$

\begin{tabular}{lll}
\hline Variable & n. & Percentage \\
\hline Age (years) & \multicolumn{2}{l}{} \\
$20-23$ & 348 & $87 \%$ \\
$24-26$ & 52 & $13 \%$ \\
Min.-Max. & $21.0-25.0$ \\
Mean \pm SD. & $22.50 \pm 1.11$ \\
Gender & \multicolumn{2}{|}{} \\
Male & 115 & $28.8 \%$ \\
Female & 285 & $71.2 \%$ \\
Educational level & \multicolumn{2}{|}{} \\
General Secondary School & 323 & $80.75 \%$ \\
Technical Nursing Institute & 77 & $19.25 \%$ \\
Previous infection control training program & \\
Yes & 139 & $34.8 \%$ \\
No & 261 & $65.2 \%$ \\
\hline
\end{tabular}

Table 2, illustrates distribution of internship students according to their overall knowledge and practice scores. It can be seen that the interns' knowledge is limited to either poor or fair $(59.5 \%, 37.3 \%)$ respectively; whereas only few percent $(3.3 \%)$ had good knowledge score. with a mean score of the knowledge is $44.93 \pm 15.59$. Regarding, the infection control practice score of the students, it was found that the majority of scores were ranging from poor and good scores $(43.2 \%, 42 \%)$ respectively, while few percent had fair score $(14.8 \%)$ with a mean score of $56.94 \pm 32.16$. 
Table 2. Distribution of internship nursing students' according to their overall score of IPC $(n=400)$

\begin{tabular}{|c|c|c|c|c|c|c|c|}
\hline \multirow{2}{*}{$\begin{array}{l}\text { Nursing interns' IPC knowledge } \\
\text { and practice }\end{array}$} & \multicolumn{2}{|c|}{ Poor score $†$} & \multicolumn{2}{|c|}{ Fair score $†$} & \multicolumn{2}{|c|}{ Good score $†$} & \multirow{2}{*}{$($ Mean \pm SD $)$} \\
\hline & n. & $\%$ & n. & $\%$ & n. & $\%$ & \\
\hline Overall knowledge score & 238 & 59.5 & 149 & 37.3 & 13 & 3.3 & $44.93 \pm 15.59$ \\
\hline Overall practice score & 173 & 43.2 & 59 & 14.8 & 168 & 42.0 & $56.94 \pm 32.16$ \\
\hline$\chi^{2}(p)$ & \multicolumn{7}{|c|}{$27.077^{*}\left(<.001^{*}\right)$} \\
\hline
\end{tabular}

Figure 1 shows the mean percent score of the internship students' response regarding knowledge of IPC. The highest observed knowledge percentage scores were for respiratory hygiene and standard precautions $(56.5 \%)$, whereas the lowest knowledge percentage scores were for using a N95 face mask as a respiratory protective device $(42.19 \%)$.

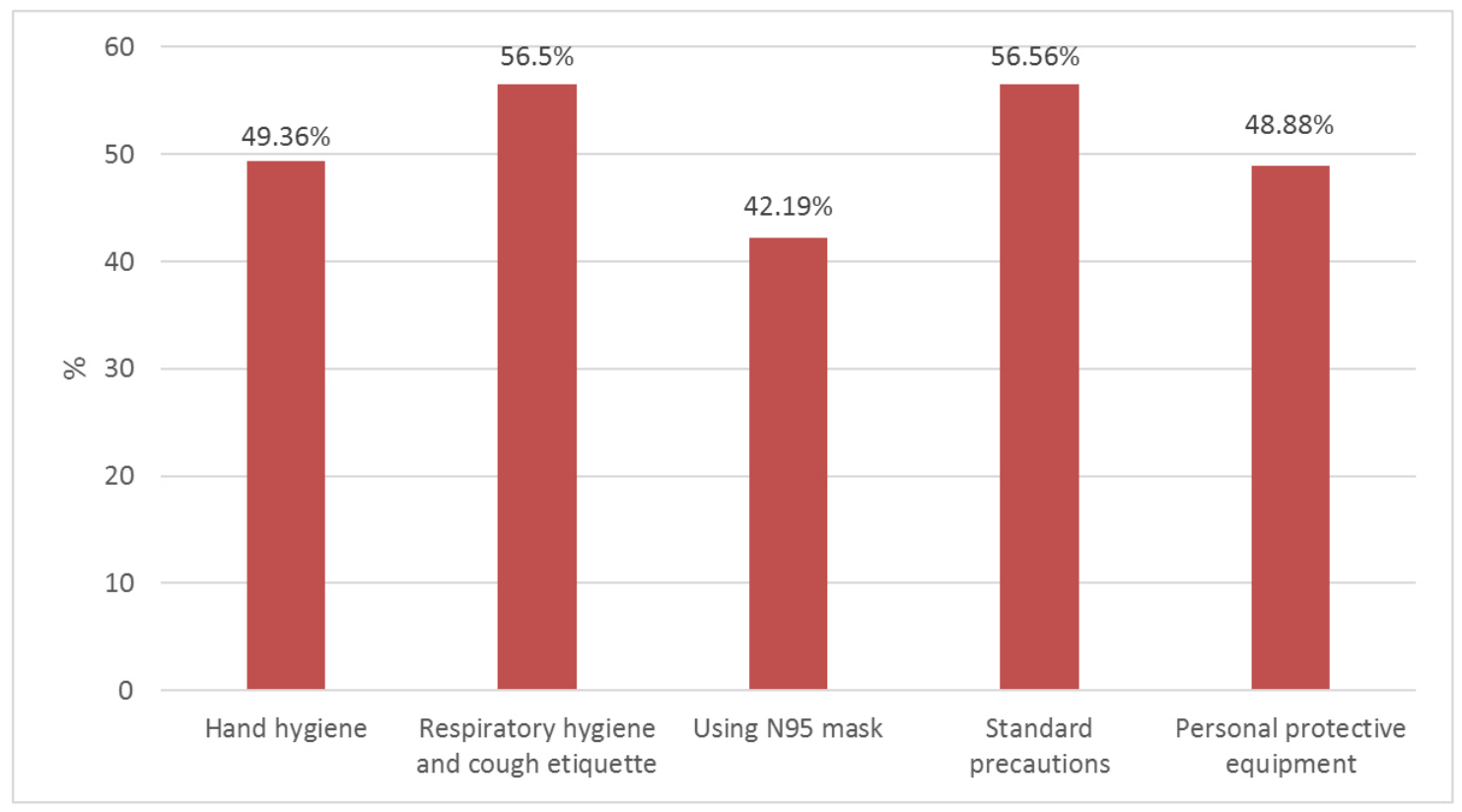

Figure 1. Mean percent scores of internship nursing student regarding knowledge of IPC

Table 3 illustrates distribution of the nursing internship satisfaction concerning IPC within nursing program. It was found that $55.3 \%$ of interns reported that infection control program is neither irrelevant nor meaningful whereas $44.7 \%$ reported that it is relevant and meaningful.

Table 3. Distribution of internship nursing students' satisfaction regarding infection prevention and control within nursing program $(\mathrm{n}=400)$

\begin{tabular}{lll}
\hline Overall satisfaction & No. & \% \\
\hline Neither irrelevant nor meaningful $\leq 70 \%$. & 221 & 55.3 \\
Relevant and meaningful $>70 \%$. & 179 & 44.7 \\
Overall satisfaction percent score & $61.82 \pm 23.46$ \\
\hline
\end{tabular}

As shown in Figure 2, internship nursing students' perspectives regarding the educational environment that support in- fection prevention and control practices. According to Figure 2(A), about one third of the interns $(30.5 \%)$ rated that the nursing faculty's environment has an excellent support to infection control behaviors; followed by $24.3 \%$ of them who stated that it was poor. Moreover, $28.3 \%$ of them reported that the clinical training environment is good for supporting infection prevention and control practices. In relation to Figure 2(B), 58.3\% of the interns reported that nurse educator's act as role models in the infection prevention and control practices. In addition, $58.3 \%$ of the interns were satisfied with their training in basic infection prevention and control measures. As for Figure 2(C), the highest interns' proportion $(48.5 \%)$ suggested that participation in infection prevention and control training program is very important for improvement of the undergraduate nursing program. 

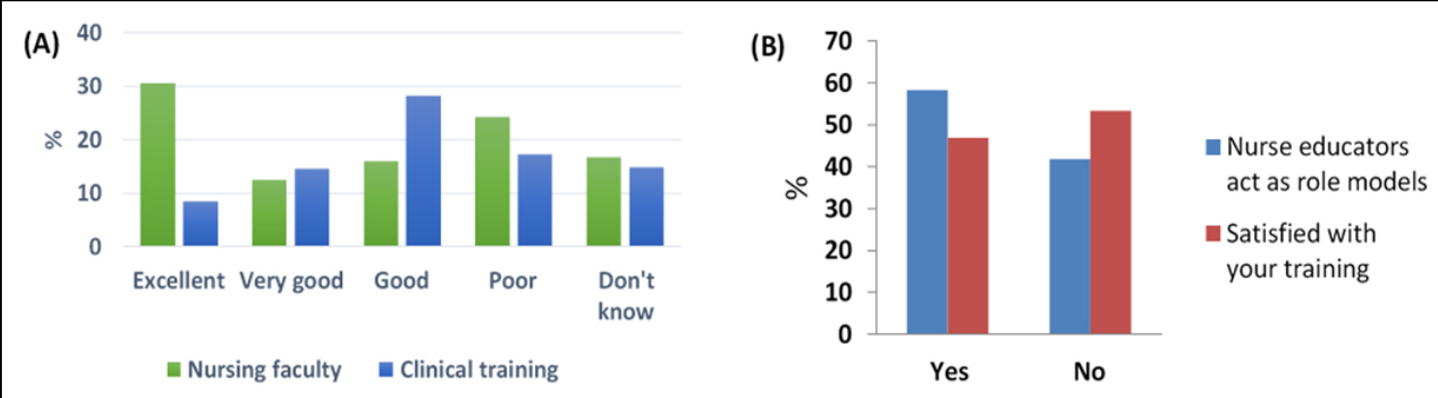

(c) Suggestions for improvement of infection prevention and control practices

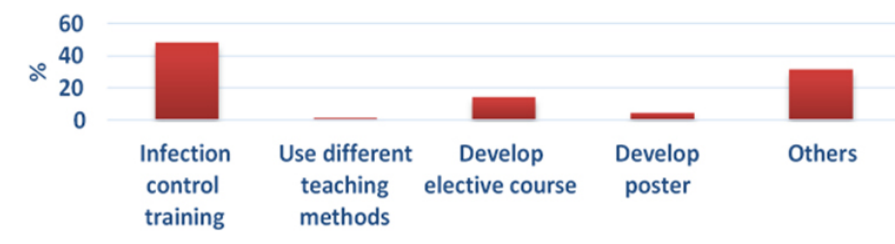

Figure 2. Internship nursing students' perspectives regarding the educational environment that support IPC

Figure 3 displays correlation between the interns' knowledge there is a significant correlation between interns' knowledge and practice. As regards to the educational environment sup- and practice $(r=.563, p<.001)$. porting infection control practices behavior, it was found that

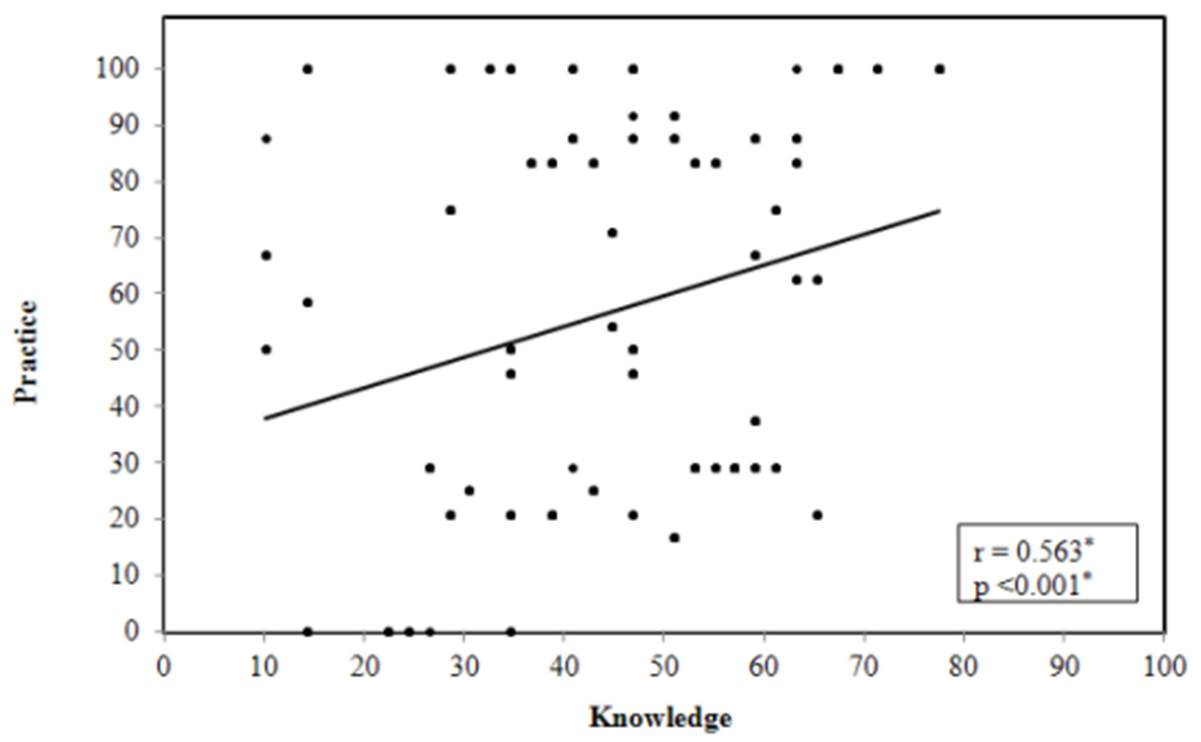

Figure 3. Correlation between the interns' knowledge and practice regarding IPC practices $(n=400)$

\section{Discussion}

IPC is one of the essential competencies for nursing graduates and for all health systems. This competency must be met over the different levels of the undergraduate nursing program.

\subsection{Knowledge and practice of IPC guidelines}

Knowledge and practice of IPC are necessary component to all novice nurses; our study reveals that there were more than half of interns had poor knowledge and nearly half of them had poor practice regarding IPC measures. Darawad and 
Al-Hussami (2013) had similar findings, which reported that Jordanian nursing students had poor knowledge regarding IPC precautions. ${ }^{[22]}$ In line with that, D'Alessandro et al. (2014) reported that $90.8 \%$ of interns had poor knowledge about infection control. ${ }^{[23]}$ Atalla et al. (2016) also found that the majority of medical surgical nursing second year academic students experienced lack in their knowledge and practices regarding universal precautions of infection control. ${ }^{[21]}$ In addition, this finding was incongruous with the study conducted by Bai (2015) who concluded that; most of the interns $(71.1 \%)$ had adequate knowledge. ${ }^{[2]}$

This current study's findings might be due to the insufficient IPC training courses in the last academic semester of undergraduate nursing program. Moreover, the time allocated to IPC units in each academic year may be not adequate, as well the intended learning outcomes of undergraduate nursing program did not contain IPC competency in its professional domain. Furthermore, the increased student-faculty ratio during clinical training may affect students' IPC competency.

Findings of the current study showed that the highest percentage scores were for respiratory hygiene and standard precautions. This is in the line with Labrague et al. study (2012) who reported that: the majority $(89.7 \%)$ of the interns have good knowledge regarding standard precautions. ${ }^{[25]}$ Moreover, the lowest percentage score was for using N95 mask that is a respiratory protective device used to eliminate the risk of respiratory infections among health care providers; which is contradicted with The Occupational Safety and Health Standards (OSHA) in 2011 reported that every health care worker has to use a respiratory PPE, such as an N95 face mask to control harmful exposures in the workplace must be trained to properly use this equipment before using it in the workplace. ${ }^{[26]}$ This could be attributed to the undergraduate nursing program which may need to be reviewed for adding more emphasis on its IPC content based on the current evidence based guidelines.

\subsection{Internship nursing students' satisfaction with the undergraduate IPC curriculum}

The results also revealed that more than half of nursing students reported that IPC curriculum is neither irrelevant nor meaningful. This is may be attributed to the nursing students who stated that the application of IPC guidelines were not adequate all over the eight levels of clinical training. In addition, more than half of students reported that they were not satisfied with training in basic IPC measures. This could be because the developing countries, including Egypt, there is also inadequate information about nurses' educational needs in the aspect of IPC. It can be noted that; in 2015, the Egyp- tian Ministry of Health and Population issued the "National Guidelines for TB Infection Control"[27] but the degree of integration of those guidelines in nursing education program was not assessed. ${ }^{[28]}$ On the other hand, Elhady et al. (2015) reported that the majority of the nursing students were interested in infection control course and agreed that the institute gives attention to infection control. ${ }^{[29]}$ However, in a study conducted by Shalaby et al. (2018) which investigated nursing student perception of safety practices in a Faculty of Nursing, that include infection prevention as a subcategory, $49 \%$ of the nursing students had poor perception regarding their unsatisfactory clinical performance whereas $56 \%$ had fair perception regarding their inconsistent nursing curricula. ${ }^{[30]}$

As for the internship nursing students' suggestions for improvement of IPC curriculum in nursing program, nearly half of them agreed that participation in IPC continuing training program was essential. This is supported by Management Sciences of Health Agency in Egypt (2015), which stated that one of the strategies adopted for improving the performance of nurses, was to ensure their implementation of infection control standards. ${ }^{[31]}$ Moreover, internship nursing students stated that using different learning and teaching strategies was useful for improving IPC curriculum in the nursing program. This may be due to the use of interactive and small group teaching which provides more opportunities for nursing students to apply IPC standards and increase retention of information. Furthermore, adding new elective course about IPC was also suggested by some nursing students.

In summary, development of educational environment that supports and encourages the effective application of IPC practices is a very important recommendation for the improvement of undergraduate nursing program through providing all facilities, materials and equipment for IPC. In addition, Storr et al. (2017) emphasized on the development of implementation strategy for the IPC core components at the level of nursing faculty and training hospitals. ${ }^{[1]}$

\subsection{Study limitations}

This study was undertaken in one university and does not therefore reflect IPC education in other universities and other countries. There can also be limitations in the use of questionnaire for assessing students' IPC practice rather than using observational checklist.

\section{Conclusion}

Although regular IPC education in undergraduate nursing program, gaps have been identified in knowledge and practice of IPC among internship nursing students. As the results revealed that infection prevention and control information 
in the undergraduate nursing education, throughout its all educational levels, may be insufficient, this needs to be updated. This highlights the need for continued training and education as well as the need for reviewing the intended learning outcomes of nursing program to ensure the proper education and implementation of infection control guidelines in all academic levels of nursing program. Furthermore, competency statements that are listed under the "Professional and practical skills" domain of nursing program specification has to comprise competency regarding IPC as "Perform nursing interventions in accordance with recognized standards of infection prevention and control guidelines".

\section{Recommendations}

- Comprehensive foundation course for IPC should be conducted prior to exposure to clinical practice in the internship year.

- ILOs of undergraduate nursing program should be reviewed and add the IPC as a core competency.
- Develop undergraduate nursing program mapping with the all undergraduate courses to link IPC in all courses.

- Clinical nurse educators should coordinate with administrative authority in the faculty of nursing to promote positive learning environment which encourage IPC.

- Follow up the nursing students for compliance/performance/utilization of standard precautions of IPC throughout the different levels including the internship year.

- Provide educational posters for reminding nursing students to comply with IPC guidelines in clinical areas and nursing labs.

- Add IPC elective course for undergraduate nursing program bulletin.

- Integrate evidence based recommendations for effective IPC practices into nursing program.

\section{Conflicts of InTEREST Disclosure}

The authors state that there is no conflict of interest.

\section{REFERENCES}

[1] National Clinical Guideline Center. Infection: prevention and control of healthcare-associated infections in primary and community care. London: 2012. Available from: https://www.ncbi.nlm.nih.g ov/books/NBK115271/pdf/Bookshelf_NBK115271.pdf

[2] Lazzari S, Allegranzi B, Concia E. Making hospitals safer: the need for a global strategy for infection control in health care settings. World Hosp Health Serv. 2004; 40(2): 32, 34, 36-42.

[3] Allegranzi B, Bagheri NS, Combescure C, et al. Burden of endemic health-care-associated infection in developing countries: systematic review and meta-analysis. Lancet. 2011; 377(9761): 228-41. https://doi .org/10.1016/S0140-6736(10)61458-4

[4] World Health Organization. Report on the burden of endemic health care-associated infection worldwide. 2011. Available from: https://apps . who.int/iris/bitstream/handle/10665/8 0135/9789241501507_eng.pdf ; jsessionid=F020D10D34B1 9EB015053DCAFB1DB246? sequence $=1$

[5] Office N.A. Reducing healthcare associated infections in hospitals in England. 2009.

[6] Zungu LI, Sengane M, Setswe KG. Knowledge and experiences of needle prick injuries (NPI) among nursing students. South African Family Practice. 2008. 50(5): 48-58. https://doi.org/10.108 0/20786204.2008.10873762

[7] Paudel I, Ghosh V, Adhikari P. Knowledge, Attitude and Practice of nursing students regarding hand hygiene in Western region of Nepal. Journal of College of Medical Sciences-Nepal. 2016; 12(4): 169-173. https://doi.org/10.3126/jcmsn.v12i4.16417

[8] Cruz JP, Bashtawi MA. Predictors of hand hygiene practice among Saudi nursing students: A cross-sectional self-reported study. Journal of Infection and Public Health. 2016; 9: 485-93. PMid:26707706 https://doi.org/10.1016/j.jiph.2015.11.010

[9] Atulomah NO, Oladepo O. Knowledge, perception and practice with regards to occupational risks of HIV/AIDS among nursing and mid- wifery students in Ibadan, Nigeria. Afr J Med Med Sci. 2002; 31(3): 223-7.

[10] Silva A, Bim L, Bim F, et al. Patient safety and infection control: bases for curricular integration. Rev Bras Enferm. 2018; 71(3): 1170-1177. PMid:29924159 https://doi.org/10.1590/0034 $-7167-2017-0314$

[11] Storr J, Twyman A, Zingg W, et al. Core components for effective infection prevention and control programmes: new WHO evidencebased recommendations. Antimicrobial Resistance \& Infection Control. 2017; 6(1): 6. PMid:28078082 https://doi.org/10.1186/ s13756-016-0149-9

[12] Wu CJ, Gardner GE, Chang AM. Taiwanese nursing students' knowledge, application and confidence with standard and additional precautions in infection control. Journal of Clin Nurs. 2009; 18: 1105-12. PMid:18647198 https://doi .org/10.1111/j.1365-2702 . 20 $08.02309 . \mathrm{x}$

[13] Kelcíkova S, Skodova Z, Straka S. Effectiveness of hand hygiene education in a basic nursing school curricula. Public Health Nurs. 2012; 29: 152-9. PMid:22372452 https://doi.org/10.1111/j. $1525-1446.2011 .00985 . x$

[14] Ward D. The Infection Prevention and Control Education of Nursing and Midwifery Students. 2015, University of Manchester.

[15] Ayub M, Goyal A, Kotwal A, et al. Infection control practices in health care: Teaching and learning requirements of medical undergraduates. Medical Journal Armed Forces India. 2013; 69(2): 107112. PMid:24600081 https://doi.org/10.1016/j.mjafi. 20 12.07 .021

[16] Ibrahim AA, Elshafie SS. Knowledge, awareness, and attitude regarding infection prevention and control among medical students: a call for educational intervention. Advances in Medical Education and Practice. 2016; 7: 505. PMid:27579002 https ://doi .org/10.2 147/AMEP.S109830 
[17] Ojulong J, Mitonga KH, Iipinge S. Knowledge and attitudes of infection prevention and control among health sciences students at University of Namibia. African Health Sciences. 2013; 13(4): 1071-1078. PMid:24940334 https://doi.org/10.4314/ahs.v13i4.30

[18] Mitchell BG, Say R, Wells A, et al. Australian graduating nurses' knowledge, intentions and beliefs on infection prevention and control: a cross-sectional study. BMC Nursing. 2014; 13(1): 43 PMid:25516721 https://doi.org/10.1186/s12912-014-004 3-9

[19] Ghalya MHA, Ibrahim Y. Knowledge, attitudes and sources of information among nursing students toward infection control and standard precautions. Life Sci J. 2014; 11(9): 249-260.

[20] Waltman PA, Schenk LK, Martin TM, et al. Effects of student participation in hand hygiene monitoring on knowledge and perception of infection control practices. Journal of Nursing Education. 2011 50(4): 216-221. PMid:21366164 https ://doi.org/10.3928/01 484834-20110228-06

[21] Atalla H, Aboalizm S. Effect of nursing guidelines compliance to infection control among nursing student. IOSR Journal of Nursing and Health Science. 2016; 5(1): 23-34.

[22] Darawad MW, Al-Hussami M. Jordanian nursing students' knowledge of, attitudes towards, and compliance with infection control precautions. Nurse Education Today. 2013; 33(6): 580-583. PMid:22789874 https ://doi.org/10.1016/j.nedt.2012.06 .009

[23] D'Alessandro D, Agodi A, Auxilia F, et al. Prevention of healthcare associated infections: Medical and nursing students' knowledge in
Italy. Nurse Education Today. 2014; 34(2): 191-195. PMid:23725909 https ://doi.org/10.1016/j.nedt.2013.05.005

[24] Bai HJ. Knowledge and Practice of Health Care Workers on Infection Control Measures. Asian Journal of Nursing Education and Research. 2015; 5(4): 518. https://doi.org/10.5958/2349-2996. 2015 .00106 .8

[25] Labrague LJ, Rosales RA, Tizon MM. Knowledge of and compliance with standard precautions among student nurses. Studies. 2012; 19: 21. https://doi.org/10.14419/ijans.v1i2.132

[26] Standards, O.S.A.H. Personal protective equipment: respiratory protection. 2011.

[27] Arab Republic of Egypt Ministry of Health and Population. National guidelines for TB Infection Control. Egypt. 2015.

[28] Walton M, Woodward H, Staalduinen S, et al. The WHO patient safety curriculum guide for medical schools. BMJ Quality \& Safety. 2010; 19(6): 542-546. PMid:21127112 https://doi.org/10.1 136/qshc. 2009.036970

[29] Elhady G, Ibrahim D, Mohamed M, et al. Improving Infection Control Practices: A Module of Education of Nurses In-Training. MiddleEast Journal of Scientific Research. 2015; 23(11): 2657-2665.

[30] Shalaby SA, Seweid MM, El-soussi AH. Critically ill patient safety in nursing education: Students' practices and perception. International Journal of Healthcare. 2018; 4(2): 1-9. https : //doi.org/ 10.5430/ijh.v4n2p1

[31] McDermott C, El-Feky W, AbdulRazik M. End of Project Performance Evaluation for USAID/Egypt: Improving the Performance of Nurses in Upper Egypt, evaluation final report. 2015. 